\title{
Features of heat treatment of grain in dryers of the contact type
}

\author{
Sergey Sutyagin ${ }^{1, *}$, Andrey Pavlushin ${ }^{1}$, and Petr Ageyev ${ }^{1}$ \\ ${ }^{1}$ Ulyanovsk State Agrarian University named after P.A. Stolypin, 432017. Ulyanovsk, Russian \\ Federation
}

\begin{abstract}
The main types of use of thermal impact on grain used in agricultural production are analyzed. The perspective patented design of energy-saving installation for grain drying is offered. The installation uses a contact method of heat supply to the processed product. The results of studies on the optimization of the main parameters of the grain drying process are presented.
\end{abstract}

Heat treatment of agricultural materials is widely used in various processes and technologies for the production, processing and storage of crop products. The analysis shows that heat treatment is widespread in many sectors of agricultural production.

For the production of cereals are widely used rice, millet, buckwheat, oats, barley, wheat, peas and corn. On the yield and quality of cereals is influenced by many indicators of quality of raw materials, filminess, fineness, uniformity, contamination, humidity etc. for Example, high humidity makes the process of cleaning the grain from impurities and flakiness, low - increases the divisibility of the kernel during processing. Therefore, an important step in the preparation of grain for processing into cereals is its heat treatment. As a result of heat treatment, the technological properties of the grain are improved: the separation of the shells is facilitated during peeling, the crushing capacity of the core is reduced, the consumer properties of the grain are improved.

After heating and moistening, partial chemical transformations take place in the grain, the core is plasticized, becomes less brittle and less crushed when peeling. Drying after steaming can increase the fragility of the outer films, which are then easier to split when peeling. The efficiency of heat treatment depends on the modes of operations, as well as on the used means of mechanization of the process. For steaming corn is usually used proparivatel continuous and intermittent operation.

In the production of vegetable oils are widely used drying seeds of oilseeds for conditioning them on moisture. The process of seed processing depends largely on the moisture content of oilseeds, which determines the effectiveness of such technological processes as the collapse, separation of the core from the shells, grinding the core, frying the pulp and extracting the oil. Therefore, it is very important to choose the optimal technological mode of drying, which is determined by the chemical composition and physical and mechanical properties of seeds, as well as the design of the drying device.

\footnotetext{
* Corresponding author: andrejpavlu@yandex.ru
} 
Thermal processing of raw materials is also used in the production of animal feed for young animals, which is not sufficiently developed enzymatic system (starch cereals for them difficult to digest-Rome). To increase digestibility included in the feed crops are subjected to heat treatment, in which part of the starch is converted into simpler carbohydrates - dextrins, maltose.

Several methods of heat treatment are known: frying, extrusion, micronization, etc.

Heat treatment due to the action of high temperature and pressure can almost completely destroy the pathogenic microflora and fungi.

The effectiveness of the process of heat processing of grain depends mainly on the design of the plant, the temperature regime and the required quality of grain preparation [1].

Today, more than a dozen foreign firms present their grain-drying equipment on the Russian market. However, it is very important that this imported equipment is adapted to the European conditions for the production, processing and storage of grain, which differ from those in Russia. For example, the average index of grain debris in Russia is $15 \%$, humidity is $22 \ldots .24 \%$, and in Europe it is $1 \ldots .2 \%$ and $19 \ldots 20 \%$, respectively. Therefore, in order to bring the grain of Russian producers to basic conditions, using imported equipment, it is necessary to perform one and the same operation several times, disrupting the flow of the entire process and increasing the energy costs of this process.

In this regard, the development of technical equipment that meets the needs of Russian grain producers, intensifying the processes of heat processing of grain, taking into account energy and resource saving, is an important and important scientific and technical task.

On the basis of the above, we set a research goal: the development of a plant for heat processing of grain with substantiation of the optimal design parameters and modes of operation, ensuring a reduction in energy costs and the required quality of the finished product at a given throughput. The object of the research was the technological process of heat processing of grain, and the subject of research was the parameters of the technological process of thermal processing of grain and the means of mechanization of this process.

The proposed installation for heat treatment was investigated in laboratory and production conditions in accordance with the applicable State Standards, OSTs and developed private methods. The experimental data obtained using the experiment planning methodology were statistically processed using the Excel, Statistika- 6 and Derive- 5 programs. The reliability of the results of the work is confirmed by the convergence of the results of theoretical and experimental studies, comparative studies of the installation in production conditions.

An installation for the heat treatment of grain (Figure 1), which can be used for drying grain and for its thermal disinfection, is proposed [2].

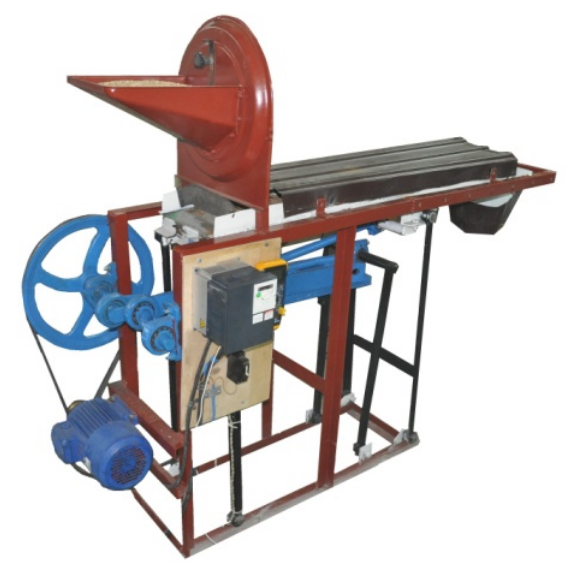

Fig. 1. Installation for heat processing of grain 
Installation is universal as it can work with grain of any agricultural crops.

After processing the results of experiments on the drying of wheat, the following regression equations were obtained in coded values of the factors for the cases:

$$
\begin{aligned}
& \text { 1) } v_{3}=0 ; Y=3103,89+88,51 x_{2}+69,93 x_{3}-234,91 x_{2}^{2}+39,51 x_{2} x_{3}+158,47 x_{3}^{2} ; \\
& \text { 2) } v_{\mathrm{B}}=0 ; Y=3042,92+1,93 x_{1}-33,09 x_{3}-2,31 x_{1}^{2}+15,26 x_{1} x_{3}+152,23 x_{3}^{2} \\
& \text { 3) } t_{\Pi}=0 ; Y=3260,85+1,82 x_{1}+165,65 x_{2}-3,31 x_{1}^{2}-17,34 x_{1} x_{2}-234,91 x_{2}^{2},
\end{aligned}
$$

where $t_{\Pi}$ - average temperature of the heating surface, ${ }^{\circ} \mathrm{C} ; v_{\mathrm{B}}$ - air velocity, $\mathrm{m} / \mathrm{s} ; v_{3}$ - grain velocity, $\mathrm{m} / \mathrm{s} ; Y$ - specific energy consumption for evaporation of moisture, $\mathrm{kJ} / \mathrm{kg} ; x_{1} ; x_{2} ; x_{3}$ - respectively, the speed of movement of the grain, the speed of air; average temperature of the heating surface in coded values of factors.

The obtained regression equations, as well as analysis of the response surfaces obtained using their two-dimensional sections (Figure 2), show that the specific heat consumption for evaporation of wheat grain moisture decreases to $q_{\min }=3042 \mathrm{~kJ} / \mathrm{kg}$ with a grain velocity of $v_{3}=0,0035 \mathrm{~m} / \mathrm{c}$, the average temperature of the casing surface is $t_{\Pi}=61,8{ }^{\circ} \mathrm{C}$. However, the resulting minimum energy consumption corresponds to unacceptable process conditions, since at $v_{3}=0,0035 \mathrm{~m} / \mathrm{s}$, the capacity of the installation does not exceed 84 $\mathrm{kg} / \mathrm{h}$, which is uneconomical [3-5]. Therefore, the optimal unit costs of heat will be considered as those at which the capacity of the installation is maximum, and the one-time moisture collection is not less than $2 \%$.

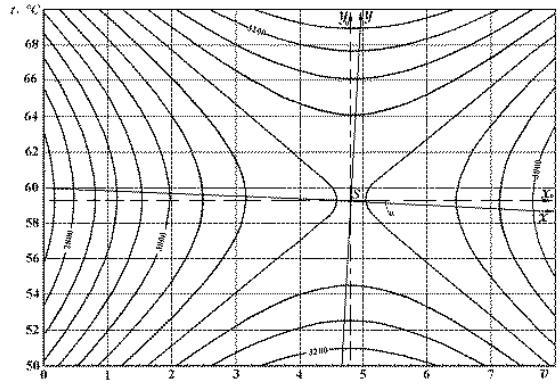

a)

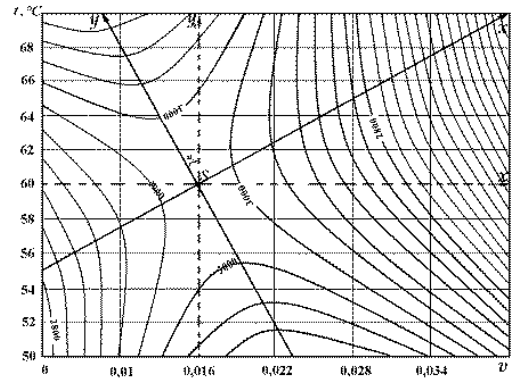

b)

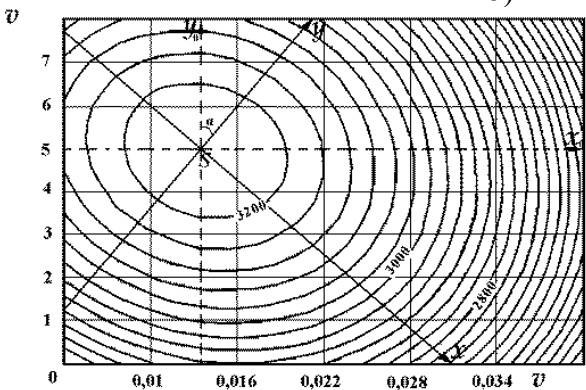

c)

Fig. 2. Two-dimensional sections of response surfaces, characterizing the specific heat consumption for moisture evaporation, $\mathrm{kJ} / \mathrm{kg}$, from the interaction: a) $t_{\mathrm{n}}$ and $v_{\mathrm{B}} ; \mathrm{b}$ ); $t_{\mathrm{\Pi}}$ and $v_{3} \mathrm{c}$ ) $v_{\mathrm{B}}$ and $v_{3}$

The optimal values of independent factors were determined when drying wheat grain: the average temperature of the heating surface was $t_{\mathrm{n}}$ opt $=58{ }^{\circ} \mathrm{C}$, the air velocity in the installation $v_{\mathrm{B}}$ opt $=5,44 \mathrm{~m} / \mathrm{s}$, the grain velocity $v_{3}$ opt $-0,033 \mathrm{~m} / \mathrm{s}$. At the same time, specific energy consumption for moisture evaporation is $q_{\text {opt }}=3102 \mathrm{~kJ} / \mathrm{kg}$. 
Measurements made during the operation of the drying unit of the electrocontact type showed that the dust concentration in the air of the operator's working area at the end of the work shift is $1,2 \ldots 1,8 \mathrm{mg} / \mathrm{m}^{3}$. This concentration does not exceed the maximum permissible for grain dust $\left(2 \mathrm{mg} / \mathrm{m}^{3}\right)$. During the operation of existing installations of convective type, the actual dust concentration in the air of the operator's working area is within $30 \ldots 50$ $\mathrm{mg} / \mathrm{m}^{3}$, which significantly exceeds the MPC [6-7].

Further improvement of the proposed installation is aimed at the proposed new design scheme. A distinctive feature of the proposed installation is that a single layer of grain is subjected to heat treatment. In addition, due to the location of the working body (perforated screw) at any angle to the horizontal, the grain in the process of movement from the hopper to the discharge window makes a complex movement along the turns of the screw, repeatedly turning around and evenly heating. This ensures high quality of grain heat treatment. The work of the proposed installation for grain heat treatment is based on the use of a combined method of heat supply to the processed grain (contact method of grain heating in combination with convective), which allows to ensure the maximum fulfillment of technological requirements for the processed grain.

The proposed installation is at least 10 times cheaper than analogues. Therefore, potential demand from small agricultural and processing enterprises can be expected. Specific energy consumption for moisture evaporation in comparison with the most effective existing drying plants is reduced by about $1.3 \ldots 1.54$ times or more. The payback period of the proposed installation does not exceed 0.53 years.

Operation of the proposed installation for grain drying in comparison with existing dryers of convective type is not only economically advantageous, but also leads to an improvement in the environmental condition, as well as working conditions of the staff.

\section{References}

1. Trisvyatsky, LA Technology of receiving, processing, storage of grain and products of its processing / L.A. Trisvyatsky, B.E. Miller. - Moscow: Kolos, 1983. - 351 p.

2. Pat. 2465527 Russian Federation, IPC F26B 17/04 (2006.01). A device for drying grain / V.I. Kurdyumov, A.A. Pavlushin, S.A. Sutyagin; Applicant and patent holder of Ulyanovsk State Agricultural Academy FGOU. - Application No. 2011119459/06, dated May 13, 2011; publ. 10/27/12, Bull. No. 30.

3. Vargas, W.L. Heat conduction in granular materials / W.L. Vargas, J.J. McCarthy // AIChE Journal. - 2001. - № 47. - Pp. 1052-1059.

3. Baum, A.E. Drying grain / A.E. Baum, V.A. Carvers. - M .: Kolos, 1983. - 223 p.

4. Yadollahinia, A.R. Design and fabrication of experimental dryer for studying agricultural products / A.R. Yadollahinia, M. Omid, S. Rafie // Int. J. Agri. Biol. - 2008. № 10. - Pp. 61-65.

5. Kurdyumov, V.I. Theoretical substantiation of the dynamics of grain drying at the contact method of heat supply / V.I. Kurdyumov, A.A. Pavlushin, G.V. Karpenko // Bulletin of the Ulyanovsk State Agricultural Academy. - 2015. - № 3 (31). - P.125-130.

6. Kurdyumov, V.I. Justification of optimal operation modes of a contact-type grain dryer / V.I. Kurdyumov, A.A. Pavlushin, S.A. Sutyagin // Bulletin of the Ulyanovsk State Agricultural Academy. - 2014. - № 4 (28). - P.160-165.

7. Wang, L.J. Rapid cooling of porous and moisture foods by using vacuum cooling technology / L.J. Wang, D.W. Sun // Trends in Food Science Technology. - 2001. - № 12. - Pp. 174-184. 